\title{
絞り機構による気体流量 計
}

\author{
芝亀吉・北 村 仁一 \\ 東洋大学工学部 川越市鯨井中野台 2100 \\ （昭和 46 年 1 月 18 日 受付)
}

\section{Gasflowmeter with Throttling Device}

\author{
Kamekichi Shiba and Jinichi Kitamura \\ (Faculty of Engineering, Toyo University, Kawagoe) \\ (Received January 18, 1971)
}

The gasflowmeter with throttling device is theoretically based upon Bernoulli's theorem. This flowmeter enables us not only to know the volume flow rate of gas by measuring temperature difference between two cross sections, but also to know the mass flow rate of gas by measuring pressure difference and temperature difference.

The apparatus used in the experiments is a Venturi tube with ratio 0.071 in area and with convergence angle of 20 degrees and divergence angle of 8.4 degrees. The experimental results, in the region of Reynolds number $2.5 \times 10^{3} \sim 19.2 \times 10^{3}$, show that the discharge coefficient for volume flow rate is $1.4 \times 2.1$ and the discharge coefficient for mass flow rate is $0.08 \sim 0.12$.

\section{1. は し がき}

絞り機構による流量計は, 差圧式流量計として液体 の流量測定によく用いられ，ときには気体の流量測定 飞る利用されている。しかし，気体流量が測定される 絞り機構による流量計は, 差圧式にかぎられているの ではなく, 温度差式のものも考学られる。

気体の密度を $\rho$, 体積流量を $Q$ とすると, 絞り機構

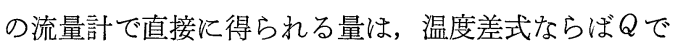
あり, 差圧式ならば $\rho Q^{2}$ である. それで, 温度差と 差圧とを測定する方式の温度差差圧式とすると, 直接 飞気体の質量流量 $\rho Q$ が得られる.

気体については, 質量流量 $\rho Q$ が知られて始めて流 量が完全に知られたことになる.

ここでは, 絞り機構として Venturi 管を使用した 流量計で実験を行ならが，オリフィス，ノズルなどで も同様である。

\section{2. 測 定 原 理}

絞り機構による気体流量計の測定原理は, 連続方程 式と Bernoulli の定理とを基礎としている. したが

$\dagger$ 第 31 回応用物理学会学術講演会で発表 (昭 $45 \cdot 10)$
って完全流体の定常流であることを仮定している.

\section{$2 \cdot 1$ 気体についての連続方程式と Bernoulli の定} 理

細い流管を考光，2 直断面を A，B とする（Fig. 1

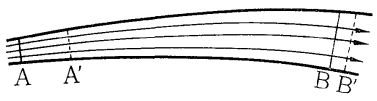

Fig. 1 Two cross sections of a stream tube

参照)。流体の密度を $\rho$, 流管の直断面積を $s$, 速度 をvとし，両断面 $\mathrm{A}, \mathrm{B}$ 飞括ける量にはそれぞれ添字 A, B をつけることにする. 連続方程式は, 質量保存の 法則を表わす式であって，この細い流管については，

$$
\rho_{s} v=\text { const. }\left(\rho_{A} s_{A} v_{A}=\rho_{B} s_{B} v_{B}\right)
$$

であ.る.

Bernoulli の定理は, 完全流体にエネルギ保存の法 則を適用することによって誘導される.

両直断面 $\mathrm{A}, \mathrm{B}$ の間にある気体にエネルギ保存の法 則を適用する。 この部分の気体のエネルギの微小時間 $d t$ 内の増加は, その間に他から加兄られたエネルギ に等しい.この部分の気体は $d t$ 時間後には断面 $\mathrm{A}^{\prime}$, $\mathrm{B}^{\prime}$ の間に移動しているとする。 その中で， $\mathrm{A}^{\prime}, \mathrm{B}$ の部 分は時間 $d t$ の前後に同じ状態の気体が存在している 
ので, $d t$ 時間内のエネルギの增加は, $\mathrm{B}, \mathrm{B}^{\prime}$ と $\mathrm{A}, \mathrm{A}^{\prime}$ との両気体部分のエネルギの差に等しい.この両部分 の質量は等しく，

$$
\rho_{A} s_{A} v_{A} d t=\rho_{B} s_{B} v_{B} d t=\rho s v d t
$$

である.この両気体部分のエネルギの差は,

運動エネルギの差 : $\frac{1}{2} \rho_{B} s_{B} v_{B}^{3} d t-\frac{1}{2} \rho_{A} s_{A} v_{A}^{3} d t$

位置エネルギの差 $: g h_{B} \rho_{B} s_{B} v_{B} d t-g h_{A} \rho_{A} s_{A} v_{A} d t$

内部エネルギの差 : $\rho s v d t c_{v}\left(T_{B}-T_{A}\right)$

の 3 者の和で与えられる， $h$ は高さ，Tは Kelvin 温 度, $c_{v}$ は気体の定積比熱である. それで $d t$ 時間内の 気体のエネルギの増加は,

$$
\rho s v d t\left\{\frac{1}{2}\left(v_{B}^{2}-v_{A}^{2}\right)+g\left(h_{B}-h_{A}\right)+c_{v}\left(T_{B}-T_{A}\right)\right\}
$$

で与えられる。

他方，活かから加えられるエネルギは，仕事と熱で ある. 完全流体であるから，管壁の括よぼす力は流れ の方向に垂直であり，その仕事は零である。 それで, 仕事は両断面 A,B に和ける圧力による力のする仕事 だけであり，ほかからの熱（管壁および両断面 $\mathrm{A}, \mathrm{B}$ からの） $H d t$ とすると，ほかから加えられたエネ ルギは,

$$
p_{A} s_{A} v_{A} d t-p_{B} s_{B} v_{B} d t+H d t
$$

である.この $(2)$ と(3)式とが互いに等しい。これを 等しいと置いた方程式を $\rho s v d t$ で割って整理すると，

$$
\begin{aligned}
& \frac{1}{2} v_{B}^{2}+g h_{B}+c_{v} T_{B}+\frac{p_{B}}{\rho_{B}} \\
& =\frac{1}{2} v_{A}^{2}+g h_{A}+c_{v} T_{A}+\frac{p_{A}}{\rho}+\frac{H}{\rho s v}
\end{aligned}
$$

となる.これが気体についての一般的な Bernoulli の 定理を表わす式である。ただし，これは完全流体とみ られる気体の定常流についての式である.

気体は分子量が $G$ の理想気体であるとする．このと きは，

$\frac{p}{\rho}=\frac{R}{G} T$ すなわち, $\frac{p_{A}}{\rho_{A}}=\frac{R}{G} T_{A}, \frac{p_{B}}{\rho_{B}}=\frac{R}{G} T_{B}$

の関係がある $(R$ は普遍気体定教である)。また，定 積モル比熱, 定圧モル比熱をそれぞれ $C_{v}, C_{p}$ とし, 定圧比熱を $c_{p}$ とすると，

$$
c_{v}+\frac{R}{G}=\frac{G c_{v}+R}{G}=\frac{C_{v}+R}{G}=\frac{C_{p}}{G}=c_{p}
$$

の関保がある.（5)式を(4)式に代入すると，

$$
\frac{1}{2} v_{B}^{2}+g h_{B}+c_{p} T_{B}=\frac{1}{2} v_{A}^{2}+g h_{A}+c_{p} T_{A}+\frac{H}{\rho s v}
$$

となる.この $(7)$ 式は, 気体が理想気体とみられるこ と，完全流体とみられること，流れが定常流であるこ との 3 条件以外には，なんの条件もなく成り立つ.な 括，時間 $d t$ 内に加兄られる熱量 $H d t$ は， A, B の間 の管壁の各部分和よび両断面 $\mathrm{A}, \mathrm{B}$ に和汸る熱の出入 の代数和としての流入熱量である.

H P S v が無視されるとする（すなわち断熱とする）. また，水平位置にあるとするので， $h_{B}=h_{A}$ である. この場合には, (7)式は,

$$
\frac{1}{2}\left(v_{B}^{2}-v_{A}^{2}\right)=c_{p}\left(T_{A}-T_{B}\right)
$$

となる.この式には，(7)式についての 3 条件のうえ に流管が水平であること, 怙よび断熱の 2 条件が必要 である.

\section{$2 \cdot 2$ 温度差式流量計の測定原理}

連続方程式 (1) 飞より,

$$
v_{B}=\frac{\rho s v}{\rho_{B} s_{B}}, \quad v_{A}=\frac{\rho s v}{\rho_{A} s_{A}}
$$

であるから，（8)式は，

$$
\frac{1}{2} \rho^{2} s^{2} v^{2}\left\{\frac{1}{\left(\rho_{B} s_{B}\right)^{2}}-\frac{1}{\left(\rho_{A} s_{A}\right)^{2}}\right\}=c_{p}\left(T_{A}-T_{B}\right)
$$

となる. $\rho Q=\rho s v$ が質量流量であるので上式から，

$$
\begin{aligned}
\rho s v & =\sqrt{\frac{2 c_{p}\left(T_{A}-T_{B}\right)}{\frac{1}{\left(\rho_{B} s_{B}\right)^{2}}-\frac{1}{\left(\rho_{A} s_{A}\right)^{2}}}} \\
& =\frac{\sqrt{2 c_{p}}}{\sqrt{\frac{1}{\left(\rho_{B} s_{B}\right)^{2}}-\frac{1}{\left(\rho_{A} s_{A}\right)^{2}}}} \sqrt{T_{A}-T_{B}}
\end{aligned}
$$

が得られる。（1)式を利用すると，(9)式は，

$$
\begin{aligned}
Q & =\frac{\sqrt{2 c_{p}}}{\sqrt{\frac{\rho_{A}^{2}}{\rho_{B}^{2} s_{B}^{2}}-\frac{1}{s_{A}^{2}}}} \sqrt{T_{A}-T_{B}} \\
& =\frac{\sqrt{2 c_{p}}}{\sqrt{\frac{1}{s_{B}^{2}}-\frac{\rho_{B}^{2}}{\rho_{A}{ }^{2} s_{A}{ }^{2}}}} \sqrt{T_{A}-T_{B}}
\end{aligned}
$$

が得られ， $\rho_{A}, \rho_{B}, T_{A}, T_{B}$ の測定によって気体の体積 流量が知られる。 さらに，(5)式を利用すると，(9) 式は,

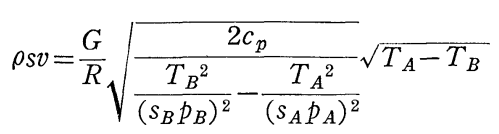

と書くことができる.これは， $T_{A}, T_{B}, p_{A}, p_{B}$ の測定 によって気体の流量が知られることを示している，た だし，実際の気体は完全流体でないために，補正とし て(11)式の右辺に係数（いわゆる流量係数） $r$ を掛け ることが必要である.

以上は，H/OSv の無視されるといら意味で断熱であ ることを条件としているが，可逆変化であることは条 
件の中にはいっていない: したがって理想気体の断熱 可逆変化について証明される Poisson の法則,

$$
\frac{p}{\rho^{\alpha}}=\text { const. }
$$

が成り立つ場合に限定されているのではない。 比熱の比である.

気体の密度の変化が少なく，のが一定とみられると する.すなわち， $\rho=\rho_{B}=\rho_{A}$ とする．このときには (10)式は,

$$
s v=Q=K \sqrt{c_{p}} \sqrt{T_{A}-T_{B}}
$$

となる，ここに，Kは装置によって定まっている定数 であって,

$$
K=\sqrt{\frac{2 s_{B}^{2} s_{A}^{2}}{s_{A}^{2}-s_{B}^{2}}}
$$

で与えられる.

(13)式に流量係数 $\alpha$ を導入した，

$$
Q=\alpha K \sqrt{c_{p}} \sqrt{T_{A}-T_{B}}
$$

が温度差式絞り流量計の測定原理を表わしている.

\section{$2 \cdot 3$ 差圧式絞り流量計の測定原理}

(5)式によって,

$$
T_{A}-T_{B}=\frac{G}{R}\left(\frac{p_{A}}{\rho_{A}}-\frac{p_{B}}{\rho_{B}}\right)
$$

であることが知られる．さらに， $\rho=\rho_{A}=\rho_{B}$ とみら れるとすると，(13)式は，

$$
\begin{aligned}
\rho Q^{2} & =K^{2} \frac{G}{R} \cdot c_{p}\left(p_{A}-p_{B}\right)=K^{2} \frac{C_{p}}{R}\left(p_{A}-p_{B}\right) \\
& =K^{2} \frac{\kappa}{\kappa-1}\left(p_{A}-p_{B}\right)
\end{aligned}
$$

となる.この(17)式は差圧 $p_{A}-p_{B}$ の測定炕よって流 量が知られることを示している.

(17)式は，気体が理想気体でしかも完全流体である といら仮定を基として導かれた式である。しかし，実 際の気体はこれらの仮定を満たしていないであろう。 そのときには，(17)式の右辺に流量係数 $\beta$ の 2 乗をか けて,

$$
\rho Q^{2}=\beta^{2} K^{2} \frac{\kappa}{\kappa-1}\left(p_{A}-p_{B}\right)
$$

とすべきである．この(18)式が差圧式絞り流量計の測 定原理を表わす式である.

(18)式を導くのに，断熱であることは仮定している が，可逆変化であることを仮定してはいない。

\section{4 温度差差圧式絞り流量計の測定原理}

気体の密度が温度, 圧力によって著しく变わるので, 質量流量が知られて初めて気体の流量が完全に知られ たことになる，それで，上記の温度差式にしても差圧 式にしても密度 $\rho$ が知られているとして, 流量が知ら れるのである.
温度差と差圧とを測定すると,(15) と(18)式との組 合わせで,

$$
\rho Q=\frac{\beta^{2}}{\alpha} K \frac{\kappa}{\kappa-1} \cdot \frac{p_{A}-p_{B}}{\sqrt{c p} \sqrt{T_{A}-T_{B}}}
$$

が得られ，質量流量 $\rho Q$ が知られる。この場合には， $c=\beta^{2} / \alpha$ を流量係数とすることができる.すなおち，

$$
\rho Q=c K \frac{\kappa}{\kappa-1} \frac{p_{A}-p_{B}}{\sqrt{c_{p}} \sqrt{T_{A}-T_{B}}}
$$

である．Kは装置による定数 $\kappa, c_{p}$ は気体の種類によ る定数である（20) 式は, 温度差 $T_{A}-T_{B}$ と, 差圧 $p_{A}-p_{B}$ との測定によって気体の質量流量が知られる ことを示している.

$\alpha, \beta$ は気体が完全流体とみられないために必要と なった流量係数である. 粘性のために, 熱の発生と圧 力の損失とがある. $s_{A}>s_{B}$ であるときには，熱の発 生があると完全流体のときより温度差が小さくなり， 圧力の損失があると完全流体のときより差圧が大きく なる。この場合には，

$$
\alpha>1, \beta<1
$$

である.したがって，

$$
c<1
$$

である.

\section{3. 実験}

絞り機構としては，円錐形 Venturi 管を使用する. 差圧式 Venturi 管流量計で気体の流量を測定するこ とは，従来も行なわれているので実験の主要目的を，

i ）温度差式流量計で気体の流量が測定できるかど らか。

ii）温度差-差圧式流量計で気体の質量流量が知ら れるかどうか。

を検討することに置いた。

\section{$3 \cdot 1$ 試作流量計}

最初の試作流量計は, Fig. 2 に示されているよう

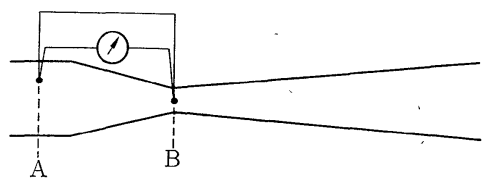

Fig. 2 First trial flowmeter

に断面 $\mathrm{A}, \mathrm{B}$ に両接合部を置いた熱電対で温度差を測 定するようにした．熱電対の両接合部の間は Venturi 管の外飞出ている. この試作流量計では, 流量と温度 差の関係が明らかでないことが実験の結果として認め られた。

これは，管壁および外部の影響が著しいためである 
と考える.このような欠点を除去するために，Venturi 管の管軸に熱電対を設置し，両接合部がそれぞ れ断面 $\mathrm{A}, \mathrm{B}$ にあるようにした。 また，断面 $\mathrm{A}, \mathrm{B}$ に 圧力取出口を設け差圧が測られるようにした． Fig. 3

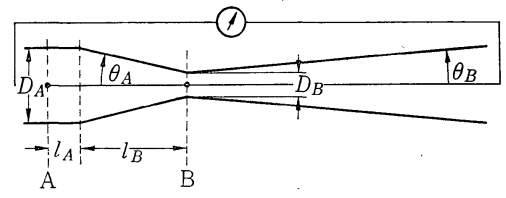

Fig. 3 Developed trial flowmeter

は試作流量計の構造の概略を示す図であり，主要寸法 快断面 $\mathrm{A}$ の内径 $D_{A}=30.0 \mathrm{~mm}$, 断面 $\mathrm{B}$ の内径 $D_{B}=$ $8.0 \mathrm{~mm}$, 流入円錐の半頂角 $\theta_{A}=10^{\circ}$, 流出円錐の半 頂角 $\theta_{0}=4.2^{\circ}$, 圧力取出口の内径 $1 \mathrm{~mm}$, 圧力取出口 の位置 (A)，(B) はそれぞれ流入円錐の底面から管軸 に沿って $l_{A}=8 \mathrm{~mm}, l_{B}=64.5 \mathrm{~mm}$ である. Venturi 管の形状は，差圧式の通常のものとだいたい同じであ る. 使用した熱電対は, 線径が $0.2 \mathrm{~mm}$ のものを 3 対で； $1 \mu \mathrm{V}$ あたり $0.00536 \mathrm{deg}$ の温度差を示す.

\section{$3 \cdot 2$ 実 験 方法}

上記の構造の試作流量計を Fig. 4 に示したよらに

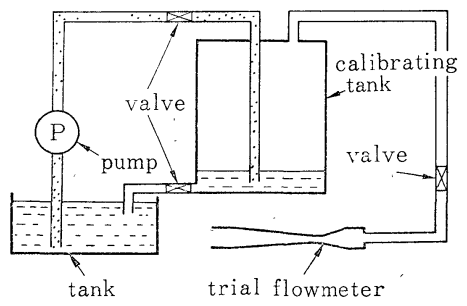

Fig. 4 Piping for experiments

連結し，タンクへ水を定常に流入させる．このとき水 は同体積の測定しょうとする気体と入れ換わるので, タンクに一定量の水が流入する時間を測定し，実験的 な体積流量（実測体積流量）を求める。断面 $\mathrm{A}, \mathrm{B}$ に 扣ける温度差 $T_{A}-T_{B}$ の測定によって理論的に(15) 式で定められる体積流量と，上述の実測体積流量との

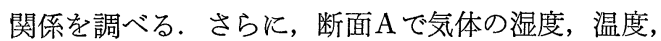
王力を測定すれば，気体の密度が定まるので質量流量 (実測質量流量) が知られる. 断面 A, B に拈ける差 圧 $p_{A}-p_{B}$, 温度差 $T_{A}-T_{B}$ の測定によって理論的 に(20)式で定められる質量流量と上述の実測質量流量 との関係を調べる.

\section{4. 実 験 結 果}

測定を行なった気体は空気である．Fig. 5 は実測 体積流量と温度差との関係を表わす。体積流量の測定

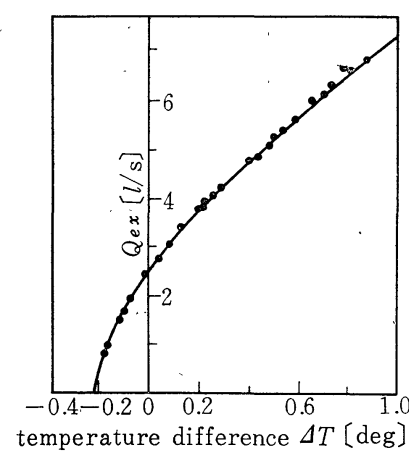

Fig. $5 \Delta T$ vs. experimental volumetric flow-rate $Q_{e x}$

範囲は 864 から $6800 \mathrm{~cm}^{3} / \mathrm{s}$ ， Reynolds 数の範囲は $2.5 \times 10^{3}$ から $19.2 \times 10^{3}$ であり，このとき，実際に

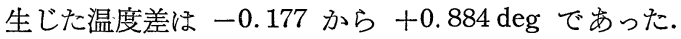
な和，体積流量が零のとき，温度差は一0.214 deg を 示した. 理論的には流量が零のとき温度差が零である はずであるが，Fig. 5 では体積流量と温度の関係は 明らかに対応している，これは，理論で仮定している 断熱であるという条件が実験では完全に満たされてい なかった原因であろらと考えられる，それで，温度差 の零点を $-0.214 \mathrm{deg}$ に移して理論的な計算を行な ってみる。まず，実測体積流量 $Q_{e x}$ と理論体積流量 $Q_{t h}$ との比較を Fig. 6 に示す. $Q_{e x}$ と $Q_{t h}$ とは等

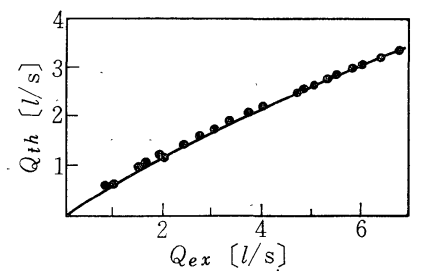

Fig. $6 Q_{e x}$ vs. theoretical volumetric flowrate $Q_{t h}$ calculated by eq. (13)

しくないが，その関係はだいたい1本の曲線で表わさ れる．絞り機構による流量計は Bernoulli の定理を 基としているが，完全流体であることなど理論の基礎 となっている仮定が実際には満たされていないので, 差圧式の場合にも流量係数を導入して補正している. 温度差式の場合にも，同様の考兇により，流量係数を 導入する. 実験体積流量と理論体積流量との比を, 流 量係数 $\alpha$ とする. 体積流量が増加するに従って流量係

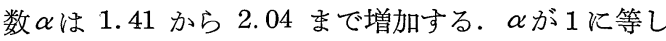
くないのは，空気が完全流体でないことのほか，体積 流量が大きくなると熱の伝導が大きくなり, 温度差 $T_{A}-T_{B}$ が小さくなることなど理論を樹立するとき に仮定した条件が満たされていないためである. 


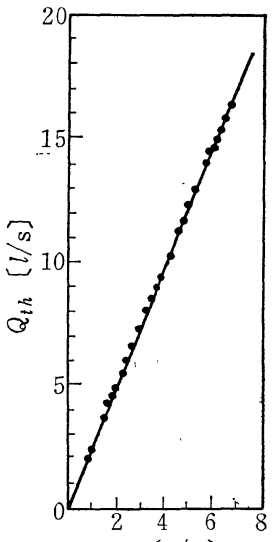

$Q_{e x}[l / s]$

Fig. $7 Q_{e x}$ vs. theoretical lvolumetric flowrate $Q_{t h}$ calculated eq. (17)
つぎに，差圧式流量計と して, 実験結果を考虑する. 理論式(18)に, 温度执よび 圧力の実測值によって得ら れた空気密度と差圧を代入 して求められる理論体積流 量 $Q_{t h}$ と実測体積流量の 比較を Fig. 7 に示す. こ のときの流量係数 $\beta$ は上述 の流量範囲で $0.41 \pm 0.005$ である。

最後に, 実測質量流量 $\rho Q_{e x}$ と理論質量流量 $\rho Q_{t h}$ の比較を Fig. 8 に示す このとき，実測質量流量の 範囲は 1.02 から $8.16 \mathrm{~g} / \mathrm{s}$, 差圧は 2.4 から 1333.3

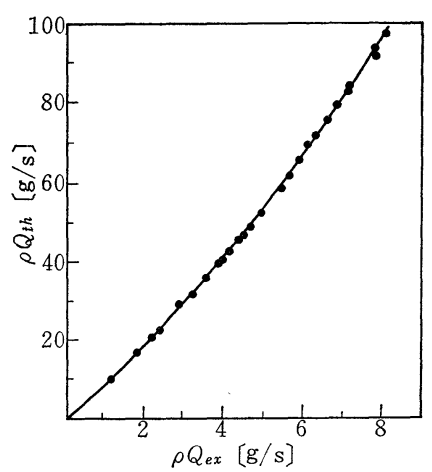

Fig. $8 \rho Q_{e x}$ vs. theoretical mass flow-rate $\rho Q_{t h}$ calculated by eq. (19)

$\mathrm{cmH}_{2} \mathrm{O}$ の範囲であった. この場合の流量係数 $c$ は実 測質量流量と理論質量流量との比であり，質量流量が 増加するに従って 0.117 から 0.084 まで減少する.

以上のような結果から, 温度差式流量計, 温度差差圧式流量計のいずれも，あらかじめ流量計を校正し て，扣の抹の流量係数を定めて和けば気体の体積流量 $Q$ は温度差 $T_{A}-T_{B}$ の測定によって知られ，気体の 質量流量 $\rho Q$ は温度差 $T_{A}-T_{B}$ と差圧 $p_{A}-p_{B}$ との 測定によって知られることが認められた.

な括, 各流量係数 $\alpha, \beta, c$ は, 理論で知られるよう に $c=\beta^{2} / \alpha$ の関係を満足している.

\section{5. 結果および考察}

上述の実験の結果によると, 温度差式でる温度差一 差圧式でも気体の流量を測定することはできるが，あ まり精度がよくない，温度差式，あるいは温度差-差
圧式流量計での測定にさいして，測定精度を高めるた めには一定流量にたいして断面 A,B での温度差を十 分に大きく得られることが望ましい，それには断面 $\mathrm{A}, \mathrm{B}$ の面積比 $s_{B} / s_{A}$ を小さくするか, または一定温 度差にたいする熱電対の出力を増加させるなどの方法 が考えられる.

試作流量計では面積比 $s_{B} / s_{A}$ を 0.071 としている. これは Venturi 管としてはかなり小さい值であり, そのために差圧式の流量係数 $\beta$ が $0.41 \pm 0.005$ と小 さくなっている. さらに, 面積比の大きさによってそ の流量計での流量測定の上限が定められるであろう.

すなわち，流量が増大すると断面 $\mathrm{A}, \mathrm{B}$ での密度が一 定であると考えられなくなる. この実験では, 最大流 量 $6800 \mathrm{~cm}^{3} / \mathrm{s}$ に対して断面 $\mathrm{A}, \mathrm{B}$ での密度変化の割 合は土 $6 \%$ 程度である.

つぎに，理論を導びく過程で断熱であることを仮定 しているが，実験結果 Fig. 5 によるとこの条件は完 全には満たされていない，そこで，さらに断熱性を良 くして実験を行なったところ，Fig. 5 に示された実 験曲線と同様の曲線でただ横軸の正の方向に 0.0536 deg だけ全体に平行移動している結果を得た。この ことは管壁拉よび断面 $\mathrm{A}, \mathrm{B}$ からの熱の出入が小さけ れば理論 (15)，(18)，(20)式を近似的に使用してもよ いことを示していると考えられる.

また，測定原理で予測されたよらに各流量係数 $\alpha$, $\beta, c$ は以下のように大小関係を満足している.

$$
\begin{array}{ll}
1<\alpha & (=1.41 \sim 2.04) \\
1>\beta & (=0.41 \pm 0.005) \\
1>c & (=0.084 \sim 0.117)
\end{array}
$$

しかし, 各流量係数はいずれも 1 よりかなり離れてい る.すべての流量係数を 1 に近づけるためには，絞り 機構, 温度差取出口の位置, 温度差測定機器の改良を 必要とするであろうし, 流量係数 $\alpha, c$ の変化を少な くするためには断熱性をさらによくするように考虑し なければならない。

\section{6. 結}

論

従来の圧力差測定方式の絞り気体流量計と異なって 温度差測定方式によっても体積流量が知られることが わかり，さらに圧力差測定を付加することで質量流量 が知られることがわかった. 被測定流体と周囲の温度 を一定に保つことができれば再現性はかなり良い.

ただし，これまでの圧力差測定方式による流量係数 及は，流量が変わってもほぼ一定に保たれるが，温度 差測定方式による流量係数 化し，したがって流量係数 $c$ も変化するので, さらに 装置の改良が必要である。また，利点と考えられるこ とはこれまでの圧力差測定方式のものより電気量に変 換することが容易な点である. 